\title{
POETAS-TRADUTORES: QUANDO A TRADUÇÃO ENCONTRA A CRIAÇÃO
}

\author{
Marlova Gonsales Aseff ${ }^{1}$ \\ Universidade Federal de Santa Catarina, Florianópolis, Santa Catarina, Brasil
}

\begin{abstract}
Resumo: Este artigo especula os motivos pelos quais muitos poetas brasileiros se dedicam à tradução de poesia ao invés de trabalharem exclusivamente em seus projetos de criação "autoral". Partimos da constatação de que os poetas foram os grandes responsáveis pela tradução e publicação de poesia estrangeira no Brasil na segunda metade do século passado e na primeira década deste século, apesar de a autoria tida como "original" ter sido considerada, pelo menos desde o Romantismo, superior ou mais digna de apreço do que a tradução. Conclui-se que os poetas que recorrem à tradução o fazem, em geral, tendo em mente pelo menos três intenções não-excludentes: a) demarcar as suas filiações ou afinidades com determinada família poética; b) proceder a um exercício de crítica e criação com a finalidade de imergir na experiência da linguagem de outro poeta; c) influenciar os cânones, apontando rumos para a poesia local. Também são abordadas outras consequências das escolhas tradutórias dos poetas-tradutores para o sistema literário local.

Palavras-chave: Poetas-Tradutores; Cânones; Tradução e Criação; Poesia Traduzida no Brasil
\end{abstract}

\section{POETS-TRANSLATORS: WHEN TRANSLATION MEETS CREATION}

\begin{abstract}
Since poets were largely responsible for the translation and publication of foreign poetry in Brazil during the second half of the $20^{\text {th }}$ Century as well as in the first decade of the ongoing century, this article speculates the reasons behind the fact that many Brazilian poets devote their time to translate rather than working exclusively on their
\end{abstract}


"original" creations. Why do they behave this way, if it is well known that at least since Romanticism authorship is considered superior or more worthy of appreciation than the works of translation? The conclusion is that poets translate generally with at least two non-excluding intentions in mind: a) demarcating their affiliations or affinities with a particular poetic family; b) undertake an exercise of criticism and creation with the aim to immerse in the language's experience of the foreign poet; c) c) influence the canons, pointing directions to local poetry. The article also addresses some consequences of poets' translation choices for the local literary system.

Keywords: Poets-Translators; Canons; Translation and Creation; Translated poetry in Brazil

\section{Poetas e a tarefa da tradução de poesia}

A importância na história literária brasileira do trabalho de tradução de poesia levado a cabo por poetas há um bom tempo tem recebido comentários esparsos e até certo reconhecimento por parte da crítica $^{1}$, mas apenas recentemente a abrangência dessa atividade foi dimensionada com maior precisão. A pesquisa "Poetas-tradutores e cânone da poesia traduzida no Brasil” (Aseff 2012) reuniu dados que demonstram que os poetas brasileiros foram os grandes responsáveis pela tradução e publicação de poesia estrangeira no Brasil entre 1960-2009 (e tudo indica que antes do período estuda-

${ }^{1}$ Bosi, na sua História Concisa da Literatura Brasileira reconhece que "em um tópico de literatura brasileira não pode faltar a referência a algumas versões de grandes poetas que começaram a falar em português à nossa sensibilidade" Menciona, ainda, a importância do surgimento de "numerosas traduções de poesia" na década de 1980 e afirma que "os bons tradutores continuam sendo poetas e ensaístas que já deram provas de concentrado labor textual em seus escritos originais" (Bosi 489-490). A História da Literatura Brasileira, de Carlos Nejar (2011), menciona a atividade tradutória de vários poetas nas biografias que integram o corpo do livro, atitude incomum até pouco tempo. Já John Milton avalia que o número de trabalhos publicados é de tal forma considerável que "esta área [poesia traduzida] deveria ser seriamente considerada um gênero da literatura brasileira contemporânea” (Milton 183). Ítalo Moriconi (1997) também deu atenção ao fenômeno da tradução de poesia no Brasil contemporâneo. 
do a dinâmica tenha sido semelhante). O levantamento relacionou um universo de $314^{2}$ tradutores de poesia no Brasil atuantes nas cinco décadas estudadas, sendo que, desses, 145 foram identificados como poetas. ${ }^{3}$ Eles traduziram praticamente sete entre cada dez livros $(69 \%)$ de poeta estrangeiro editados nesse meio século pesquisado e estiveram envolvidos em $73 \%$ das antologias, no papel de tradutores e/ou de organizadores (Aseff 76-77). Sobre tal fato, em meados da década de 1990, Ítalo Moriconi, ao tratar do lugar ocupado pela tradução entre os poetas brasileiros, munido de grande sensibilidade histórica, sentenciou:

Hoje, o ato de batismo do poeta brasileiro não é mais a publicação dos seus primeiros poemas em suplementos literários - estes deixaram de existir ou foram substituídos por suplementos 'culturais'. A certidão do poeta passou a ser dada pela publicação de tradução de poema estrangeiro (Moriconi 304).

Por certo, esse não é um fenômeno exclusivamente brasileiro nem limitado a este período da história. David Connolly lembra que "sempre houve uma conexão muito próxima entre escrever poesia original e traduzi-la, e os maiores poetas são geralmente tradutores e preocupados com os problemas teóricos envolvidos (Connolly 175, tradução nossa). ${ }^{4}$ Ezra Pound, por exemplo, um dos poetas-tradutores mais relevantes do século 20, exerceu influência decisiva no projeto dos poetas concretos brasileiros, que encararam a tradução como uma militância para estabelecer e firmar os seus

\footnotetext{
${ }^{2}$ Esse número subiu para 360 quando da publicação de um catálogo revisado e expandido no site Poesia Traduzida no Brasil (www.poesiatraduzida.com.br).

${ }^{3} \mathrm{O}$ critério para ser considerado poeta foi o de ter pelo menos um livro autoral de poesia publicado.

4 "There has always been a close connection between writing original poetry and translating it, and major poets are often themselves translators and concerned with the theoretical issues involved" (Connolly 175)
} 
modelos poéticos. No entanto, no período imediatamente anterior, poetas das três fases do modernismo brasileiro, como Manuel Bandeira, Cecília Meireles, Henriqueta Lisboa, Guilherme de Almeida, Abgar Renault, Péricles Eugênio da Silva Ramos e Geir Campos, entre outros, também se dedicaram à tradução com afinco. Se retrocedermos ainda mais na história, seguiremos encontrando poetas e escritores brasileiros atuando como tradutores.

Consideramos válido, portanto, especular sobre os motivos que levaram e ainda levam tantos poetas brasileiros a se dedicarem à tradução ao invés de trabalharem exclusivamente em seus projetos autorais. Mesmo que a autoria dita "original" seja considerada, pelo menos desde o Romantismo, "superior" ou mais digna de apreço do que a tradução, a cada década, mais poetas brasileiros têm assumido a tarefa da tradução como complementária à criação autoral. ${ }^{5}$ Para isso, reunimos alguns depoimentos de poetas-tradutores de várias épocas e nacionalidades que falaram sobre as suas relações com a tradução.

\section{As categorias de tradução e de criação}

Sabemos que, ao longo da história ocidental, nem sempre houve a diferenciação radical entre tradução e criação a ponto de se considerar a primeira como uma produção secundária e de menor valor. Por exemplo, a escrita medieval era muito centrada no comentário e no reordenamento de textos existentes. Antoine Berman (91) lembra que a distinção entre um texto original e um texto secundário (tradução, comentário, recriação, adaptação) não existia verdadeiramente na Idade Média, fato que só começa a mudar no Renascimento, quando aparecem as noções de original e de autor tais como a conhecemos hoje. Berman esclarece que "o Renascimento integra a tradução den-

${ }^{5}$ Em Aseff (2012), pode-se perceber um aumento do envolvimento dos poetas com a tradução. Nos anos 1960, foram computados 20 poetas-tradutores, 18 nos anos 1970, 34 nos 80, 50 nos anos 1990 e 57 nos anos 2000.

Cad. Trad., Florianópolis, v. 40, n⿳0 3, p. 92-108, set-dez, 2020. 
tro de um gênero mais vasto, cobrindo todo o campo da escrita: a imitação. Nessa época, todo texto é fundamentalmente imitação de outros textos, passados ou contemporâneos, textos que ao imitá-los, podem ser igualados ou até ultrapassados (Berman 91). Jorge Luis Borges também, em vários de seus textos, colocou em xeque tanto a questão da supremacia da autoria como o caráter secundário da tradução. Em "Las versiones homéricas”, de 1932, qualificou como "superstição" o fato de se acreditar que sempre o original será superior à sua tradução. Borges sugere que uma tradução pode, sim, superar o original e festeja a riqueza representada pela existência de diversas versões de um mesmo texto (Borges 239).

Hoje, no entanto, as categorias de criação e de tradução permanecem separadas, embora cada vez mais se aceite, pelo menos nos redutos intelectualizados, novos termos, como os criados por Haroldo de Campos. Ele explica que o seu projeto implicou

[...] uma cunhagem neológica de termos especificadores: recriação, transcriação, reimaginação (caso da poesia clássica chinesa), transparadisação ou transluminação (Seis Cantos do Paradiso de Dante) e transluciferação mefistofáustica (Cenas Finais do Segundo Fausto de Goethe).

Tudo isso, segundo o poeta-tradutor, serviu para "polemizar com a ideia naturalizada de tradução literal, fiel ou servil, vista quase sempre como uma atividade subalterna diante do texto original" (Campos and Paz 184-185).

Haroldo, baseado em Albrecht Fabri e em Max Bense, assumiu que a informação estética era mesmo, em princípio, impossível de ser traduzida e, por isso mesmo, reivindicou a possibilidade de sua recriação.

Admitida a tese da impossibilidade em princípio da tradução de textos criativos, parece-nos que esta engendra o corolário da possibilidade, também em princípio, da recria- 
ção desses textos. Teremos, como quer Bense, em outra língua, uma outra informação estética, autônoma, mas ambas estarão ligadas entre si por uma relação de isomorfia: serão diferentes enquanto linguagem, mas, como os corpos isomorfos, cristalizar-se-ão dentro de um mesmo sistema (Campos 24).

\title{
3. Motivos para traduzir
}

Por que os poetas traduzem com tanto afinco, o que os atrai nesta tarefa? Susan Bassnett e Bush acreditam que o potencial inovador da tradução está entre as respostas possíveis para explicar a dedicação dos mesmos. Ocorre que, muitas vezes, a tradução pode assumir a função de um exercício de estilo para quem cria:

\begin{abstract}
Quando um escritor usa o seu tempo para traduzir algo escrito por outro escritor, há sempre uma boa razão para tal decisão, seja para experimentar modos alternativos de escrita ou tentar alargar os limites de seu próprio estilo. $\mathrm{Ou}$ pode ser que o texto que o escritor está traduzindo seja um daqueles que ele ou ela desejariam ter escrito antes, ou seja, traduzir aquele trabalho é o próximo degrau lógico no desenvolvimento da própria escrita (Bassnett and Bush 7, tradução nossa). ${ }^{6}$
\end{abstract}

Giacomo Leopardi manifestou posição semelhante em trechos do Zilbadone di Pensieri, escrito entre 1817 e 1832, obra que reú-

\footnotetext{
6 "When a writer takes the time to translate something written by another writer, there is always a good reason for such a decision, whether it is to experiment with alternative modes of writing or to try and push the boundaries of one's own style. Or it may simply be that the text a writer is translating at any particular time is one that he or she wishes they could have written in the first instance, in other words, translating that work is a logical next step in one's writerly development." (Bassnett and Bush 7).
} 
ne ensaios sobre temas muito variados, entre eles, a tradução. O poeta, que era também tradutor, defendia a prática da tradução para os escritores iniciantes como uma forma de se aprender a compor com estilo. Segundo Andréia Guerini, através de sua teoria da tradução, Leopardi tenta demonstrar que "o ofício do tradutor está diretamente relacionado com o do escritor" (Guerini 11). Marco Lucchesi explica que, no seu caso, "a tradução de poesia tornou-se uma demanda interna do processo de criação" (Lucchesi 71). A mesma posição é exposta pelo poeta-tradutor brasileiro Paulo Henriques Britto quando diz:

Não há melhor laboratório para a criação poética do que a tradução de poesia. O trabalho de recriar no seu próprio idioma a experiência poética vivida numa língua alheia apresenta ao poeta-tradutor todos os problemas formais da criação poética, fornecendo-lhe apenas um ponto de partida de natureza já textual, o que nem sempre é o caso quando se trata de compor um poema novo. ${ }^{7}$

Para o poeta-tradutor Ivan Junqueira (1934-2014) ${ }^{8}$, a tradução de poesia poderia chegar a exigir maior empenho do poeta do que a própria criação autoral.

A rigor e sem exagero, a tradução exige esforço mais extenso e intenso do que a criação propriamente dita, sobretudo quando se trata do traslado de textos poéticos, nos quais, além de todas as especificidades [...], resta ainda ao tradutor o desafio de interpretar o pensamento do autor, sem falar nos problemas de atmosfera poética, que é necessário recriar em outra língua, e, intimamente vinculado a estes,

\footnotetext{
${ }^{7}$ Este texto consta da orelha do livro do também poeta-tradutor Adalberto Müller (2003).

${ }^{8}$ Junqueira traduziu ao português brasileiro Baudelaire, Dylan Thomas e a obra completa de T.S. Eliot.
} 
o da escolha do vocabulário, pois há palavras que podem suscitar uma sugestão poética em determinada língua e em outra, não, caso se trate de uma tradução literal. É nesse resgate de equivalências que reside o mérito de qualquer tradução. E pode-se dizer até que a maior virtude de qualquer espécie de tradução é não dar nunca a impressão de que o foi (Junqueira $\mathrm{s} / \mathrm{p}$ ).

Entrar em contato com outras tradições literárias por meio da tradução pode ter um efeito libertador para o trabalho criativo, conforme atesta o poeta-tradutor Nelson Ascher:

Creio que muitos poetas aprendem línguas e leem autores estrangeiros justamente para tentar sair da camisa-de-setevaras em que nossos antecessores nos colocaram. Um poeta como Drummond fez tanta coisa - e tão bem - que, para quem quer escrever seus próprios poemas, isso se torna quase assustador, castrante mesmo: ' $O$ que existe ainda para se escrever depois dele (ou de Bandeira, Cabral, Vinícius, Haroldo, Décio, Augusto, Gullar)?' Quando parece não haver mais saída, visitar outras épocas ou lugares é sempre refrescante (Leão s/p) .

Junqueira afirmava que, no seu caso, o exercício da crítica e da tradução também respondiam às exigências de uma estratégia que desde sempre ele se impôs:

Não restringir-me apenas à minha produção poética, mas, através do que escreveram outros poetas em outras línguas, instrumentar-me cada vez mais no que toca ao meu ofício. E não é pouco o que tenho aprendido quer traduzindo, quer escrevendo ensaios sobre a poesia alheia (Aguiar s/p). 


\section{4. É preciso ser poeta para traduzir poesia?}

José Paulo Paes defendia que a tradução de poesia é "o caso limite da problemática geral da tradução"; e que, por isso, "é no seu desempenho que o estatuto do tradutor mais se aproxima do estatuto do autor" (Paes 45). Junqueira afirmava que o tradutor de poesia deveria ser também poeta:

A primeira exigência que se deve fazer a um tradutor de
poesia é a de que ele seja um poeta, pois somente assim po-
derá enfrentar os desafios técnicos específicos desse gênero
literário, como os do ritmo, da estrutura sintático-verbal,
dos esquemas métricos e rítmicos, da linguagem metaló-
gica, do jogo de imagens e metáforas e de todos os outros
elementos que constituem a retórica poética (Junqueira $s / \mathrm{p}$ ).

Já Octavio Paz tem opinião levemente discordante. Ele diz que "em teoria, só os poetas deveriam traduzir poesia", mas que "na realidade poucas vezes os poetas são bons tradutores. Isso porque quase sempre usam o poema alheio como um ponto de partida para escreverem o seu poema." E conclui: "o bom tradutor de poesia é um tradutor que, ademais, seja bom poeta [...]; ou um poeta que seja também bom tradutor" (Paz 155). Como se vê, o poeta, por vezes, poderia estar mais interessado no seu processo individual do que em entregar uma "boa" tradução.

Assim como Paz, Honig (8) acredita que entre as questões inquietantes neste domínio está a de se pensar em que medida um poeta descobre a sua "voz" no poeta traduzido ou o quanto da "voz" do outro poeta ele toma para si. Ou, em outras palavras, quando lemos uma tradução de poesia, quanto há ali da dicção do poeta-tradutor e quanto do poeta traduzido? Connolly igualmente destaca que "muitos poetas-tradutores conhecidos tendem a impor o seu próprio estilo tão profundamente aos poemas traduzidos que esses parecem seus próprios poemas, ao invés de refletir as carac- 
terísticas particulares do autor" (Connolly 175, tradução nossa). ${ }^{9}$ Além do mais, cada poeta poderá interpretar o poema de forma diferente. José Lira, poeta-tradutor de Emily Dickinson e de Bashô, explica como vê a questão:

Entendo de forma positiva a 'inspiração' na tradução de um poema, não como a manifestação exterior de algo inefável, mas como o resultado de uma íntima luta interior com o 'estado de leitura' momentâneo de um texto poético qualquer com o qual o tradutor se propõe a trabalhar. Cada vez que alguém lê um poema, o faz de forma diferente, com base em sensações, impressões e reflexões limitadas ao instante da leitura. Esse fato produz modos distintos de interpretação na mente do tradutor e o levam a distintas reformulações e recontextualizações. ${ }^{10}$

Paz afirma que "a tradução de poesia é uma operação análoga à criação poética”. Para ele, tradução e criação são operações gêmeas: "por um lado, como demonstram os casos de Baudelaire e de Pound, a tradução é muitas vezes indistinguível da criação; por outro, há um incessante refluxo entre as duas, uma contínua e mútua fecundação" (Paz 157). O depoimento do poeta-tradutor Julio Castañon Guimarães também ilustra bem essa proposição:

\begin{abstract}
Naturalmente seria um despropósito dizer que a tradução desses autores [que traduzi], em alguns casos tão distintos, e justamente por isso, interfere no meu próprio trabalho de poesia. Mas da colocação 'tradução desses autores', se retirar a ênfase de 'autores' e transferi-la para 'tradução' já se começa a admitir a possibilidade de uma inter-relação entre as duas práticas. Naturalmente, procedimentos de alguns
\end{abstract}

9 "Many well-known poet-translators tend to impose their own style so thoroughly on the translated poems that these resemble their own poems rather than reflecting the particular characteristics of the author." (Connolly 175).

${ }^{10}$ Depoimento à Marlova Aseff em 10/5/2012. Arquivo pessoal. 
desses poetas, algumas de suas noções, terão contribuído para o conhecimento e a prática que venho tentando desenvolver no campo da poesia. Mas é de fato o exercício da tradução que mais diretamente fornece contribuições. Na medida em que traduzir implica destrinchar um texto para recompô-lo em outra língua, isto redunda em que se percebam ou se fique conhecendo vários dos elementos que constituem o poema, vários dos procedimentos que culminaram na constituição daquele texto (Cavalcanti s/p).

\section{O peso das escolhas dos poetas-tradutores na literatura nacional}

Anthony Pym afirma ser evidente que os tradutores têm importância na história da tradução (e, por conseguinte, na história literária), mas que é difícil estabelecer exatamente qual é o seu papel em termos coletivos ou individuais. Uma das suas hipóteses é que os tradutores são "active effective causes", ou seja, sujeitos que intervêm na história e exercem um tipo de influência ou poder (Pym 161). Mas quais seriam as formas pelas quais os tradutores costumam intervir na história e exercer tal poder? Uma das possibilidades seria: quando escolhem o que irão traduzir. Susana Kampff Lages afirma que "é preciso lembrar que por trás das motivações pelas quais certas obras adquirem importância em certas culturas, está a opção de certos escritores ou tradutores por traduzir determinadas obras" (Lages 88). Em relação aos escritorescríticos, Leyla Perrone-Moisés conclui que "ao escolher falar de certos escritores do passado e não de outros, os escritores-críticos efetuam um primeiro julgamento. Assim fazendo, cada um deles estabelece a sua própria tradição e, de certa maneira, reescreve a história literária" (11). Acredito que o mesmo se pode dizer das escolhas tradutórias dos poetas brasileiros que vêm exercitando a tradução com certa regularidade. 
A ideia de tradução como crítica difundida pelos poetas concretos ressalta justamente o poder da escolha e o caráter militante da tradução:

Como ato crítico a tradução de poesia não é uma atividade indiferente, neutra, mas - pelo menos segundo a concebo supõe uma escolha, orientada por um projeto de leitura, a partir do presente da criação, do passado de cultura. É um dispositivo de atuação e atualização da poética sincrônica. Assim é que só me proponho traduzir aquilo que para mim releva em termos de um projeto (que não é apenas meu) de militância cultural (Campos and Paz 63-64).

Poder-se-ia objetar que o tradutor nem sempre tem autonomia de escolha. Porém, mesmo quando não é ele quem escolhe a obra a ser traduzida, pode ainda decidir de que forma irá traduzir (o repertório empregado, a estratégia tradutória, o projeto de tradução), obviamente que sempre limitados pelo contexto histórico e social, as normas, como no conceito empregado por Toury (94-112). Os tradutores, portanto, seriam detentores de tal poder. Poder esse que, conforme resume Venuti, somando-se a escolha do texto e da estratégia tradutória, "pode mudar ou consolidar cânones literários e paradigmas conceituais [...] na cultura doméstica" (Venuti 131).

O tradutor, como promotor desse intercâmbio entre literaturas, movimenta-se num espaço de intersecção entre culturas e línguas. ${ }^{11}$ E o tradutor que igualmente atua como poeta ou escritor, assume dois papéis: o de importador de textos e o de produtor em seu sistema literário. Por isso, saber se um tradutor de poesia é também poeta transforma-se em um fator relevante de análise, pois esse fato trará consequências ao sistema literário em questão. Como a tradução de poesia se processa numa operação profunda no interior da linguagem, que se materializa na operação de "desmontar" e "remontar" um poema, é possível sugerir que nessas circunstân-

${ }^{11}$ Isso não quer dizer que sua relação com ambas as culturas seja simétrica. 
cias (quando um poeta traduz outro) seja bem maior a chance de novos modelos serem inseridos com sucesso em um dado sistema literário. O contrário também é verdadeiro: o poeta-tradutor poderá também adaptar a poética do autor estrangeiro aos modelos predominantes em seu meio literário.

Em ambos os casos, o escritor ou poeta, ao incursionar pela tradução, atua na seleção do bem estrangeiro que passará a fazer parte do espaço nacional e empresta uma marcação a esse texto. Pensando nos tipos de cânone propostos por Even-Zohar (1990), temos que os poetas-tradutores, além de incluir a obra traduzida no sistema literário nacional, também tendem a introduzir um novo repertório aprendido e exercitado no processo de tradução no seu trabalho poético autoral. Se levarmos em conta a tipologia de Alistair Fowler (1982), teremos que o trabalho do poeta-tradutor disponibiliza novas obras (cânone acessível) e, de certa forma, essas recebem o aval, em boa parte dos casos, do nome que assina a tradução.

Outro aspecto a ser levado em conta é o interesse de quem "se apropria" de um autor por meio da tradução. Ou, como lembra Pierre Bourdieu, "publicar aquilo de que eu gosto é reforçar a minha posição no campo" $(6 \text {, tradução nossa })^{12}$. O poeta- tradutor relaciona o seu nome ao do autor traduzido, fortalecendo a sua persona poética e ligando a sua imagem à do autor traduzido. Como resumiu Valery Larbaud, o tradutor "ao mesmo tempo em que amplia a sua riqueza intelectual, enriquece a literatura nacional e honra seu próprio nome" (Larbaud 73). Também as editoras, por vezes, procuram ligar o nome de um determinado escritor ou poeta à obra traduzida, por acreditar que o público o identifica com um dado gênero ou estilo literário.

\section{Conclusão}

Este trabalho partiu de reflexões iniciadas na pesquisa "Poetastradutores e cânone da poesia traduzida no Brasil (1960-2009)"

12 "Faire publier ce que j'aime, c'est renforcer ma position dans le champ [...]".

Cad. Trad., Florianópolis, v. 40, n⿳0 3, p. 92-108, set-dez, 2020. 
(Aseff 2012), que quantificou o peso do trabalho tradutório de poetas na divulgação da poesia estrangeira traduzida no Brasil. O objetivo desta vez foi especular as motivações dos poetas ao se dedicarem à tarefa da tradução. Por meio de alguns depoimentos de poetas-tradutores, foi possível perceber que, em parte, esta é a maneira que os mesmos encontram para se aproximar de determinada tradição, buscando o significado do seu fazer artístico. Como disse T.S. Eliot, "nenhum poeta, nenhum artista de área alguma tem seu completo significado sozinho" (Eliot s/p). Ele ressaltava que esse era um princípio de crítica estética e não meramente histórica. ${ }^{13}$

Portanto, é possível dizer que a tradução pode ser uma forma eficiente de se filiar a uma tradição, a uma estética, a uma família poética, além de intervir em cânones e formar novas tradições. Pode-se concluir igualmente que a tradução de poesia abarca uma forte dimensão de criação, e que os poetas que recorrem à tradução o fazem, em geral, tendo em mente pelo menos três intenções não-excludentes: a) demarcar as suas filiações ou afinidades com determinada família poética; b) proceder a um exercício de crítica e de criação que tem como finalidade imergir na experiência da linguagem do outro poeta; e c) influenciar os cânones vigentes, apontando rumos para a poesia local.

\section{Referências}

Aguiar, Cláudio. "Entrevista com Ivan Junqueira: 'a poesia brasileira de hoje é muito superior à que se escreve em outras línguas"”. Jornal de poesia. 8/12/2019. Disponível em: http://www.jornaldepoesia.jor.br/claudi02.html.

13 "No poet, no artist of any art, has his complete meaning alone. His significance, his appreciation is the appreciation of his relation to the dead poets and artists. [...] I mean this as a principle of æsthetic, not merely historical, criticism.” 
Aseff, Marlova. "Poetas-tradutores e o cânone da poesia traduzida no Brasil (1960-2009)”. Tese Universidade Federal de Santa Catarina, 2012.

Bassnett, Susan; Bush, Peter. The translator as writer. London/New York: Continuum, 2006.

Berman, Antoine, Marie Hélène C. Torres, \& Marlova Aseff. "De la translation à la traduction/ Da translação à tradução." Scientia Traductionis, 0.9 (2011): 71-100. 04/8/2019. Disponível em: https://periodicos.ufsc.br/index.php/scientia/ article/view/1980-4237.2011n9p71.

Borges, Jorge Luis. Obras completas I. Barcelona: RBA Instituto Cervantes, 2005.

Bosi, Alfredo. História concisa da literatura brasileira. São Paulo: Cultrix, 2006.

Bourdieu, Pierre. "Les conditions sociales de la circulation internationale des idées". Actes de la Recherche en Sciences Sociales, nº. 145, (2002): 3-8. Portal da École Normale Supérieure de Lyon. 12/11/2019. Disponível em: https://www. persee.fr/doc/arss_0335-5322_2002_num_145_1_2793.

Campos, Haroldo de; Paz, Octávio. Transblanco. 2.ed. São Paulo: Siciliano, 1994.

Campos, Haroldo de. Metalinguagem. São Paulo: Cultrix, 1976.

Cavalcanti, Jardel Dias. "Entrevista com o poeta Julio Castañon Guimarães". Digestivo Cultural, 02/12/2019. Disponível em: http://www.digestivocultural. com/colunistas/coluna.asp?codigo $=1010$.

Conolly, David. "Poetry translation”, Encyclopedia of translation studies, Baker, Mona (ed.). London and New York: Routledge, 2001: 170-176.

Eliot, T.S. "Tradition and the individual talent". Poetry Foundation. 05/12/2019. Disponível em: https://www.poetryfoundation.org/articles/69400/tradition-andthe-individual-talent. 
Even-Zohar, Itamar. "Polysystem studies". Poetics Today - International Journal for Theory and Analysis of Literature and Communication 11.1 (1990).

Fowler, Alastair. Kinds of literature: an introduction to the theory of genres and modes. Harvard University Press, 1982.

Guerini, Andréia. Gênero e tradução no Zibaldone de Leopardi. São Paulo: Edusp; Florianópolis: UFSC/PGET, 2007.

Honig, Edwin. The Poet's Other Voice: Conversations on Literary Translation. Amherst: The University of Massachusetts Press, 1985.

Junqueira, Ivan. “A poesia é traduzível?” Digestivo cultural. 24/11/2019. Disponível em: http://www.digestivocultural.com/ensaios/ensaio.asp?codigo $=315 \&$ titul o=A_poesia_e_traduzivel.

Lages, Susana Kampff. Walter Benjamin: tradução e melancolia. São Paulo: Edusp, 2002.

Larbaud, Valery. Sob a invocação de São Jerônimo. Tradução de Joana Angélica D’Ávila Melo e João Angelo Oliva. São Paulo: Mandarim, 2001.

Leão, Rodrigo de Souza. "Nelson Ascher: entrevista concedida a Rodrigo de Souza Leão". Jornal de Poesia. 24/11/2019. Disponível em: http://www. jornaldepoesia.jor.br/nah03.html.

Lucchesi, Marco. Palavra de escritor-tradutor. Entrevista a Andréia Guerini e Karine Simoni. Florianópolis: Escritório do Livro, 2017.

Milton, John. "Translated Poetry in Brazil 1965-2004". Revista Brasileira de Lingüística Aplicada v. 4, n. 1 (2004).

Moriconi, Italo. "Pós-modernismo e tradução de poesia em inglês no Brasil". Cânones e contextos: anais do $5^{\circ}$ Congresso da Abralic. Rio de Janeiro, Abralic, (1997): 303-309.

Müller, Adalberto. Enquanto velo teu sono. São Paulo: 7Letras, 2003. 
Nejar, Carlos. História da literatura brasileira - Da carta de Caminha aos contemporâneos. São Paulo: Leya, 2011.

Paes, José Paulo. Tradução, a ponte necessária. Aspectos e problemas da arte de traduzir. São Paulo: Ática, 1990.

Paz, Octavio. Convergências - Ensaios sobre arte e literatura. Tradução de Moacir Werneck de Castro. Rio de Janeiro: Rocco, 1991.

Perrone-Moisés, Leyla. Altas literaturas. São Paulo: Companhia das Letras, 1998.

Pound, Ezra. ABC da Literatura. Tradução de Augusto de Campos e José Paulo Paes. $11^{\text {a }}$ edição. São Paulo: Cultrix, 2006.

Pym, Anthony. Method in translation history. St Jerome Publishing, 1998.

Toury, Gideon. Los estudios descriptivos de traducción y más allá. Metodología de la investigación en estudios de traducción. Traducción de Rosa Rabadán y Raquel Meino. Madrid: Cátedra, 2004.

Venuti, Lawrence. Escândalos da tradução. Tradução de Laureano Pelegrin et al. Bauru: Edusc, 2002.

Recebido em: 08/03/2020

Aceito em: 28/06/2020

Publicado em setembro de 2020

Marlova Gonsales Aseff. E-mail: marlova.aseff@gmail.com. ORCID: https:// orcid.org/0000-0001-6188-3386. Financiamento CAPES. 